\title{
Characteristics of nosocomial infection and its effects on the survival of chemotherapy patients with advanced non-small cell lung cancer
}

\author{
LILI WANG ${ }^{1}$, YAN LI $^{2}, \mathrm{XIA} \mathrm{ZHANG}^{3}$ and HONGXIA LI ${ }^{4}$ \\ ${ }^{1}$ Department III of Oncology, and Departments of ${ }^{2}$ Hospital Infection-Control, ${ }^{3}$ Obstetrics and ${ }^{4}$ Senior Cadres, \\ Binzhou City Central Hospital, Binzhou, Shandong 251700, P.R. China
}

Received June 1, 2017; Accepted September 27, 2017

DOI: $10.3892 / \mathrm{ol} .2017 .7144$

\begin{abstract}
The present study was planned to investigate the characteristics of nosocomial infection and its effects on the survival in advanced non-small cell lung cancer (NSCLC) patients. Retrospective analysis was performed for the 169 chemotherapy patients with NSCLC and nosocomial infection during hospitalization in Binzhou City Central Hospital from March, 2013 to January, 2015. In addition, 170 patients without nosocomial infection were also involved as a control group. The distribution of major drug resistance of Gram-negative $\left(\mathrm{G}^{-}\right)$and Gram-positive $\left(\mathrm{G}^{+}\right)$ were analyzed. The survival conditions of the patients were analyzed according to the nosocomial infection occurrence. The risk factors of nosocomial infection in patients with NSCLC were analyzed by univariate and multivariate logistic analysis. The percentage of $\mathrm{G}^{+}$infection was $45.6 \%$ while $\mathrm{G}^{-}$infection was $54.4 \%$. Nosocomial infections were most common in respiratory system. The median survival time of the observation group was shorter than that of the control group $(\mathrm{P}<0.05)$. $\mathrm{G}^{-}$infection was the most common type of infection in nosocomial infection of the patients with NSCLC. The occurrence of infection seriously affected the survival time of patients. Attention is required to the patients older than 60 years undergoing treatment with glucocorticoids as well as immunosuppressive agents.
\end{abstract}

\section{Introduction}

Lung cancer involves malignant tumors with highest morbidity and mortality rates thought the world. Further, rising levels of

Correspondence to: Dr Lili Wang, Department III of Oncology, Binzhou City Central Hospital, 6 Tangfang Street, Huimin, Binzhou, Shandong 251700, P.R. China

E-mail:wb22kw@163.com

Key words: non-small cell lung cancer, nosocomial infection, effects on survival environmental pollution and the effects of smog on respiratory system could not be underestimated, especially in China $(1,2)$. The incidence of lung cancer in the next few decades is expected to further rise (3). According to pathological classification, lung cancer could be divided into small cell lung cancer and non-small cell lung cancer (NSCLC). NSCLC accounts for more than $80 \%$ of cases. Also, more than $2 / 3$ of NSCLC patients are diagnosed at advanced stage. So, the diagnostics are poor and the 5-year survival rate of this disease is extremely low (4).

Previous studies have confirmed that lung infection due to nosocomial infection is a common cause of death in patients with advanced lung cancer. The antibiotic-based treatment is the main treatment approach for the lung cancer patients with pulmonary infection (5). The effect of conventional antibiotic treatment is limited with the emergence of drug resistance. So, it would be of significant value to understand the distribution of drug resistance in patients with advanced lung cancer. This approach could further improve the treatment effect and extend their survival time (6). The present study summarized the characteristics of nosocomial infection in chemotherapy patients with advanced NSCLS. We also discussed the impact of nosocomial infection on the survival of patients.

\section{Materials and methods}

General information. Retrospective analysis was used to analyze the information of the 169 chemotherapy patients with NSCLC and nosocomial infection during hospitalization; 170 patients without nosocomial infection were also involved as a control group. All the patients were diagnosed as non-small cell lung cancer by fiberoptic bronchoscopy and biopsy. All the patients in observation group had nosocomial infection. There were 126 males and 44 females in the observation group. The ages ranged from 45 to 70 with a mean age of $61 \pm 1.0$ years. The duration of disease ranged from 3 months to 2 years with a mean value of $5.1 \pm 0.2$ months. Other clinical data of the patients in observation group included length of hospitalization, invasive operation, combination of two or more medical diseases, the use of prophylactic antibiotics, use of glucocorticoids and immunosuppressive agents. The patients with immune system disease and the patients who were combined 
with malignant tumors were excluded. The study obtained approval from the Ethics Committee of Binzhou City Central Hospital and all the participants signed the informed consent before enrollment.

Observation indicators. The distribution of pathogens in nosocomial infection in patients with advanced NSCLC was statistically analyzed. The distribution of major drug resistance of Gram-negative $\left(\mathrm{G}^{-}\right)$and Gram-positive $\left(\mathrm{G}^{+}\right)$ were analyzed. The survival conditions of the patients were studied. The risk factors of nosocomial infection in patients with NSCLC were analyzed by univariate and multivariate logistic analyses.

Bacterial culture and species identification. According to the 'National Clinical Laboratory Procedures', routine testing methods were utilized. Drug susceptibility test was performed by paper diffusion method (K-B method). CLSI 2008-2010 operation procedures and result evaluation standards were used. Columbia blood plate, MH plates, identifying culture medium and drug sensitive slips were provided by the Oxoid (London, UK). The quality control strains viz. Staphylococcus aureus ATCC 25923, Pseudomonas aeruginosa ATCC 27853 and Escherichia coli ATCC 25922 were provided by provincial CDC clinical laboratory test center. The KB method is mainly used for the detection of ampicillin, cefotaxime, cefepime, ceftazidime, imipenem, clindamycin, vancomycin, erythromycin, roxithromycin, gentamicin and amikacin. The corresponding biological reagents were procured from Hangzhou Tianhe Microoragnism Reagents Co., Ltd. (Hangzhou, China). MH agar plates were stored at $4^{\circ} \mathrm{C}$ before use. Technicians with $>5$ years laboratory experience had performed all operations in strict accordance with the instructions.

Survey methods. The investigators were trained in a unified manner. The informed consent of the respondents was obtained. The investigators were familiar with the contents of the questionnaire and solutions to the frequently asked questions. Reliability coefficient was applied with values ranged from 0 to 1 . The reliability of this study was 0.996 . Two tests were performed using the same questionnaire on all subjects with an interval of 30 days to obtain the stability coefficient.

Statistical analysis. SPSS 21.0 software was utilized for statistical analyses (IBM, Armonk, NY, USA). The data were expressed as mean \pm standard deviation. The $t$-test was used to compare the mean of the two groups. The $\chi^{2}$ test was used to compare the rates of the two groups. The univariate and multivariate logistic regression analysis was used for the analysis of correlation between the factors and the disease. $\mathrm{P}<0.05$ was considered as statistically significant.

\section{Results}

The distribution of pathogens in nosocomial infection in chemotherapy patients with advanced NSCLC. $\mathrm{G}^{+}$infection accounted for $45.6 \%$ cases. Staphylococcus aureus and coagulase-negative staphylococci were the most common species. The proportion of $\mathrm{G}^{-}$infection was $54.4 \%$, of which
Table I. The distribution of pathogens in nosocomial infection in chemotherapy patients with advanced NSCLC.

\begin{tabular}{lcc}
\hline Pathogen species & $\begin{array}{c}\text { No. of } \\
\text { strains (n) }\end{array}$ & $\begin{array}{c}\text { Proportion } \\
(\%)\end{array}$ \\
\hline $\mathrm{G}^{+}$ & & 45.6 \\
Staphylococcus aureus & 41 & 24.3 \\
Coagulase-negative & 36 & 21.3 \\
Staphylococcus & & \\
$\mathrm{G}^{-}$ & & 54.4 \\
Pseudomonas aeruginosa & 27 & 16.0 \\
Klebsiella pneumoniae & 23 & 13.6 \\
Escherichia coli & 19 & 11.2 \\
Enterobacter cloacae & 14 & 8.3 \\
Enterobacter aerogenes & 9 & 5.3 \\
\hline
\end{tabular}

$\mathrm{G}^{+}$, Gram-positive; $\mathrm{G}^{-}$, Gram-negative; NSCLC, non-small cell lung cancer.

Table II. The main drug resistance distribution of $\mathrm{G}^{-}[\mathrm{n}(\%)]$.

\begin{tabular}{lcc}
\hline Antibiotics & $\begin{array}{c}\text { Pseudomonas } \\
\text { aeruginosa } \\
(\mathrm{n}=27)\end{array}$ & $\begin{array}{c}\text { Klebsiella } \\
\text { pneumoniae } \\
(\mathrm{n}=23)\end{array}$ \\
\hline Cefotaxime & $13(48.1)$ & $5(21.7)$ \\
Cefepime & $9(33.3)$ & $6(26.1)$ \\
Ceftazidime & $9(33.3)$ & $6(26.1)$ \\
Amikacin & $6(22.2)$ & $4(17.4)$ \\
Ciprofloxacin & $15(55.6)$ & $5(21.7)$ \\
Levofloxacin & $7(25.9)$ & $6(26.1)$ \\
Imipenem & $7(25.9)$ & $0(0)$ \\
Meropenem & $6(22.2)$ & $0(0)$ \\
Sulfamethoxazole & $16(59.3)$ & $11(47.8)$ \\
Gentamicin & $12(44.4)$ & $9(39.1)$ \\
\hline
\end{tabular}

$\mathrm{G}^{-}$, Gram-negative.

Pseudomonas aeruginosa and Klebsiella pneumoniae were most common (Table I).

The main drug resistance distribution of $G$ - The most common drug-resistant antibiotics for Pseudomonas aeruginosa were sulfamethoxazole, ciprofloxacin and cefotaxime, while the most common drug-resistant antibiotics for Klebsiella pneumoniae infection were sulfonamides and gentamicin (Table II).

The main drug resistance distribution of $G^{+}$. The most common drug-resistant antibiotics for Staphylococcus aureus were penicillin $\mathrm{G}$, ampicillin and sulfamethoxazole, while the most common drug-resistant antibiotics for coagulase-negative staphylococci were penicillin $\mathrm{G}$, ampicillin and sulfamethoxazole. Both of the $\mathrm{G}^{+}$bacteria were sensitive to vancomycin and teicoplanin, and even more sensitive to imipenem or meropenem (Table III). 
Table III. The main drug resistance distribution of $\mathrm{G}^{+}[\mathrm{n}(\%)]$.

\begin{tabular}{lcc}
\hline & $\begin{array}{c}\text { Staphylococcus } \\
\text { aureus } \\
(\mathrm{n}=41)\end{array}$ & $\begin{array}{c}\text { Coagulase- } \\
\text { negative } \\
\text { Antibiotics }\end{array}$ \\
\hline Penicillin G & $40(97.6)$ & $35(97.2)$ \\
Ampicillin & $39(95.1)$ & $34(94.4)$ \\
Erythromycin & $18(43.9)$ & $11(30.6)$ \\
Roxithromycin & $19(46.3)$ & $9(25.0)$ \\
Vancomycin & $0(0)$ & $0(0)$ \\
Teicoplanin & $0(0)$ & $0(0)$ \\
Sulfamethoxazole & $23(56.1)$ & $20(55.6)$ \\
Gentamicin & $12(29.3)$ & $11(30.6)$ \\
Ciprofloxacin & $11(26.8)$ & $16(44.4)$ \\
Levofloxacin & $17(41.5)$ & $13(36.1)$ \\
\hline G ${ }^{+}$Gram-positive. & & \\
\hline
\end{tabular}

Table IV. The characteristics of distribution of nosocomial infection sites.

\begin{tabular}{lcc}
\hline Infection sites & $\begin{array}{c}\text { Infection cases } \\
\text { (case) }\end{array}$ & $\begin{array}{c}\text { Infection rate } \\
(\%)\end{array}$ \\
\hline Respiratory system & 102 & 60.4 \\
Digestive system & 35 & 20.7 \\
Urinary system & 51 & 30.2 \\
Blood system & 21 & 12.4 \\
Skin and soft tissue & 10 & 5.9 \\
Other parts & 3 & 1.8 \\
\hline
\end{tabular}

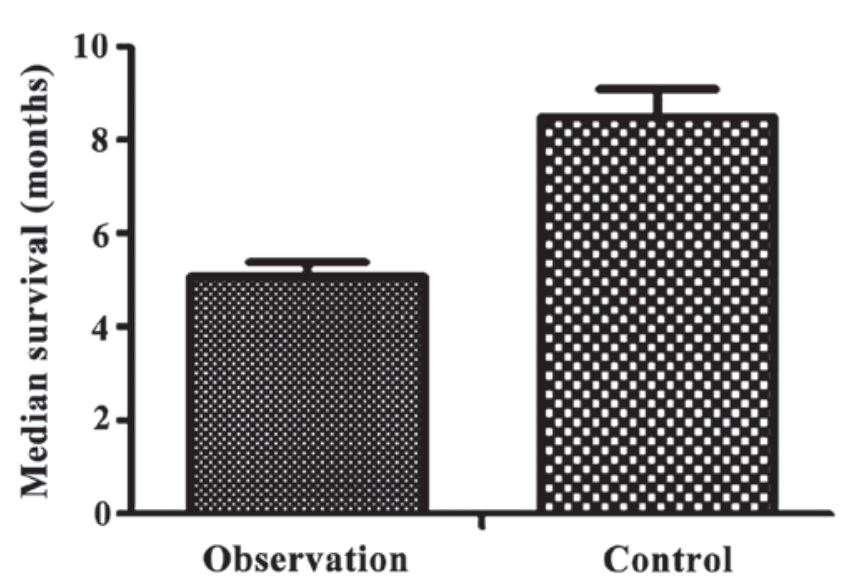

Figure 1. The characteristics of distribution of nosocomial infection sites.

The characteristics of distribution of nosocomial infection sites. Nosocomial infections were most commonly found in respiratory system followed by the urinary system and digestive system, infections in skin, soft tissue and other parts (such as intracranial infection and intra-articular infection) (Table IV).
Table V. Analysis of risk factors of nosocomial infection in patients with advanced NSCLC.

\begin{tabular}{|c|c|c|}
\hline Risk factors & Cases & Infection rate $(\%)$ \\
\hline \multicolumn{3}{|l|}{ Sex } \\
\hline Male & 125 & 74.0 \\
\hline Female & 44 & 26.0 \\
\hline \multicolumn{3}{|l|}{ Age (years) } \\
\hline$\geq 60$ & 100 & 59.2 \\
\hline$<60$ & 69 & 40.8 \\
\hline \multicolumn{3}{|c|}{ Length of hospitalization } \\
\hline$\geq 30$ days & 95 & 65.1 \\
\hline$<30$ days & 74 & 34.9 \\
\hline \multicolumn{3}{|c|}{ Invasive operation } \\
\hline Yes & 115 & 68.0 \\
\hline No & 54 & 32.0 \\
\hline \multicolumn{3}{|c|}{$\begin{array}{l}\text { Combination of two or } \\
\text { more medical diseases }\end{array}$} \\
\hline Yes & 100 & 59.2 \\
\hline No & 69 & 40.8 \\
\hline \multicolumn{3}{|c|}{$\begin{array}{l}\text { Preventive use of } \\
\text { antimicrobial agents }\end{array}$} \\
\hline Yes & 75 & 44.4 \\
\hline No & 94 & 55.6 \\
\hline \multicolumn{3}{|c|}{ Use of glucocorticoids } \\
\hline Yes & 123 & 72.8 \\
\hline No & 46 & 27.2 \\
\hline \multicolumn{3}{|c|}{$\begin{array}{l}\text { Use of immunosuppressive } \\
\text { agents }\end{array}$} \\
\hline Yes & 111 & 65.7 \\
\hline No & 58 & 34.3 \\
\hline
\end{tabular}

NSCLC, non-small cell lung cancer.

Comparison of the survival conditions between observation group and control group. The median survival time of the observation group was $5.1 \pm 0.3$ months, while the median survival time of the control group was $8.5 \pm 0.6$ months. Therefore, the median survival time of the observation group was significantly shorter than that of the control group $(\mathrm{t}=65.928, \mathrm{P}<0.05)$ (Fig. 1). The median survival time of the observation group was $5.1 \pm 0.3$ months, while the median survival time of the control group was $8.5 \pm 0.6$ months. So, the median survival time of the observation group was significantly shorter than that of the control group $(\mathrm{t}=65.928$, $\mathrm{P}<0.05)$.

Analyses of risk factors of nosocomial infection in patients with advanced with NSCLC. Invasive operation, combination of two or more diseases, the use of glucocorticoids and immunosuppressive agents in the course of treatment were observed 
Table VI. Multivariate logistic analysis of nosocomial infection in patients with advanced NSCLC.

\begin{tabular}{lcccrr}
\hline Independent risk factors & $\begin{array}{c}\text { Partial regression } \\
\text { coefficient }\end{array}$ & $\begin{array}{c}\text { Standard } \\
\text { error }\end{array}$ & P-value & OR value & $\chi^{2}$ value \\
\hline Age over 60 years & 0.321 & 0.203 & 0.012 & 1.025 & 6.361 \\
Invasive operation & 0.565 & 0.256 & 0.002 & 0.785 & 10.253 \\
Combination of two or more medical diseases & 0.296 & 0.134 & 0.032 & 1.323 & 4.377 \\
Preventive use of antimicrobial agents & -0.326 & 0.135 & 0.004 & 0.811 & 6.581 \\
Use of glucocorticoids & 0.409 & 0.158 & 0.003 & 0.623 & 8.956 \\
Use of immunosuppressive agents & 0.713 & 0.135 & $<0.05$ & 2.305 & 21.309 \\
\hline
\end{tabular}

NSCLC, non-small cell lung cancer.

commonly for NSCLC patients who were older than 60 years and have been hospitalized for 30 days or more (Table V).

Multivariate logistic analysis of nosocomial infection in patients with advanced NSCLC. Multivariate regression analysis showed that age over 60 years, invasive operation, combination of two or more diseases, the use of glucocorticoids and immunosuppressive agents were independent risk factors for nosocomial infection in patients with advanced NSCLC (Table VI).

\section{Discussion}

The concurrent chemo-radiotherapy is the main clinical treatment method for elderly patients with advanced lung cancer. However, cancer therapies result in reduced tolerance and immune capacity in patients $(7,8)$. This compromised immune capacity resulted in high chances of nosocomial infection. In addition, lung cancer is usually combined with a variety of medical diseases. In elderly patients, the organ dysfunction and decreased immunity made them prone to various complications (9). The infection is extremely harmful for patients and could even lead to death. Previous studies have confirmed that nosocomial infection has become a serious threat to patients with advanced NSCLC leading to death (10). Therefore, the infection in these patients due to long-term chemo-radiotherapy is a difficult problem for the clinicians to solve. The aim of the present study was to analyze the characteristics of nosocomial infection and its impact on the survival of patients with advanced NSCLC during chemotherapy.

In the present study, pathogens of nosocomial infection have shown that $\mathrm{G}^{-}$infection is the main type of infection. Further, the mechanism of the emergency of drug resistance of Pseudomonas aeruginosa is complex. It could be explained by the ability of Pseudomonas aeruginosa to colonize with high variability (11). While the Klebsiella pneumoniae is a common extended-spectrum $\beta$-lactamases (ESBLs) strain, the gene of lactamases is the main cause of drug resistance. Klebsiella pneumoniae could produce lactamases for plasmid binding and transduction, which led to the emergency of drug resistance (12). This study found that the $\mathrm{G}^{-}$Klebsiella pneumoniae and Pseudomonas aeruginosa were highly sensitive to imipenem and meropenem. Infection may not be effectively controlled in $\mathrm{G}^{-}$infected patients with advanced NSCLC but it could lead to serious consequences. So imipenem or meropenem could be considered for early treatment of the above patients. $\mathrm{G}^{+}$infection is sensitive to vancomycin and teicoplanin. Thus, imipenem or meropenem could be considered for the early treatment of $\mathrm{G}^{+}$infected patients with advanced NSCLC.

The increased causes of respiratory infection may be due to the special anatomical structure of the respiratory system, the location of primary lesions and the use of ventilator treatment. Collectively this made the nosocomial infection pathogens penetration easier into the body through the respiratory tract. In addition, urinary tract infection may be related to the indwelling catheter in patients (13), longterm bed rest, prostatitis in elderly male patients $(14,15)$ and reproductive system inflammation in elderly female patients $(16,17)$. Gastrointestinal infections may be related to toxic side effects of chemotherapy, especially myelosuppression (18). The occurrence of nosocomial infections, regardless of the infection site, severity, affected the quality of life in the form of reduced body rehabilitation ability and less outdoor activities.

Our study on risk factors related to nosocomial infection in patients older than 60 years has shown that self-management ability, immunity capacity, bone marrow hematopoietic function and nutritional status were gradually decreased. Especially the combination of more than two kinds of medical diseases could significantly reduce the body anti-infective ability. So, toxic effects of radiotherapy and chemotherapy become more prominent causing increased incidence of nosocomial infection (19-21). Invasive operation itself is the source of iatrogenic infection. The implementation of persistent thoracic drainage on the patients with severe pleural effusion could lead to the loss of albumin leading to decline in immune capacity. Prolonged treatment with indwelling drainage and retrograde injection are other factors responsible for nosocomial infection. The use of glucocorticoids and immunosuppressive agents could significantly inhibit the body's immune capacity leading to nosocomial infection.

In conclusion, $\mathrm{G}^{-}$infection is the dominant type of nosocomial infection in patients with advanced NSCLC. G- infection, in respiratory system is sensitive to imipenem or meropenem and the infection seriously affect the survival of patients. 


\section{References}

1. Takagi Y, Hosomi Y, Oshita F, Okamoto H, Seki N, Minato K, Aono H, Yamada K, Okuma Y, Hida N, et al: Feasibility study of docetaxel plus bevacizumab as first line therapy for elderly patients with advanced non-small-cell lung cancer: Thoracic Oncology Research Group (TORG) 1014. BMC Cancer 15: 740-750, 2015.

2. Kanda S, Horinouchi H, Fujiwara Y, Nokihara H, Yamamoto N, Sekine I, Kunitoh H, Kubota K, Tamura T and Ohe Y: Cytotoxic chemotherapy may overcome the development of acquired resistance to epidermal growth factor receptor tyrosine kinase inhibitors (EGFR-TKIs) therapy. Lung Cancer 89: 287-293, 2015

3. Chen J, Chen J, Ding HY, Pan QS, Hong WD, Xu G, Yu FY and Wang YM: Use of an artificial neural network to construct a model of predicting deep fungal infection in lung cancer patients. Asian Pac J Cancer Prev 16: 5095-5099, 2015.

4. Huang BT, Lu JY, Lin PX, Chen JZ, Kuang Y and Chen CZ: Comparison of two RapidArc delivery strategies in stereotactic body radiotherapy of peripheral lung cancer with flattening filter free beams. PLoS One 10: e0127501, 2015.

5. Kubota K, Sakai H, Katakami N, Nishio M, Inoue A, Okamoto H, Isobe $\mathrm{H}$, Kunitoh H, Takiguchi Y, Kobayashi K, et al; Tokyo Cooperative Oncology Group: A randomized phase III trial of oral S-1 plus cisplatin versus docetaxel plus cisplatin in Japanese patients with advanced non-small-cell lung cancer: TCOG0701 CATS trial. Ann Oncol 26: 1401-1408, 2015.

6. Zhuang X, Herbert JM, Lodhia P, Bradford J, Turner AM Newby PM, Thickett D, Naidu U, Blakey D, Barry S, et al: Identification of novel vascular targets in lung cancer. Br J Cancer 112: 485-494, 2015.

7. Morichika D, Sato-Hisamoto A, Hotta K, Takata K, Iwaki N, Uchida K, Minami D, Kubo T, Tanimoto M and Kiura K: Fatal Candida septic shock during systemic chemotherapy in lung cancer patient receiving corticosteroid replacement therapy for hypopituitarism: A case report. Jpn J Clin Oncol 44: 501-505, 2014.

8. Saito M, Saito W, Kanda A, Ohguro H and Ishida S: A case of paraneoplastic optic neuropathy and outer retinitis positive for autoantibodies against collapsin response mediator protein-5, recoverin, and $\alpha$-enolase. BMC Ophthalmol 14: 5-10, 2014.

9. Gómez MT, Jiménez MF, Aranda JL, Rodríguez M, Novoa NM and Varela G: The risk of bilobectomy compared with lobectomy: A retrospective analysis of a series of matched cases and controls. Eur J Cardiothorac Surg 46: 72-75, 2014.

10. Andreas S, Rittmeyer A, Hinterthaner M and Huber RM: Smoking cessation in lung cancer-achievable and effective. Dtsch Arztebl Int 110: 719-724, 2013.
11. Fernández Lorente A, Acosta Brooks S, Neninger Vinageras E, Barroso Alvarez MC, Wilkinson Brito B, Troche Concepción M, Martínez Pérez LB, Viada González CE, Crespo Diaz T and Casacó Parada AR: Effect of blockade of the EGF system on wound healing in patients vaccinated with CIMAvax ${ }^{\circledR}$ EGF. World J Surg Oncol 11: 275, 2013.

12. Goss GD, O'Callaghan C, Lorimer I, Tsao MS, Masters GA, Jett J, Edelman MJ, Lilenbaum R, Choy H, Khuri F, et al: Gefitinib versus placebo in completely resected non-small-cell lung cancer: Results of the NCIC CTG BR19 study. J Clin Oncol 31: 3320-3326, 2013

13. Huang YH, Terabe M, Pendleton CD, Stewart Khursigara D, Bera TK, Pastan I and Berzofsky JA: Identification and enhancement of HLA-A2.1-restricted CTL epitopes in a new human cancerantigen-POTE. PLoS One 8: 643-665, 2013.

14. Yang Ai SS, Hsu K, Herbert C, Cheng Z, Hunt J, Lewis CR and Thomas PS: Mitochondrial DNA mutations in exhaled breath condensate of patients with lung cancer. Respir Med 107: 911-918, 2013.

15. Noro R, Yoshimura A, Yamamoto K, Miyanaga A, Mizutani H, Minegishi Y, Seike M, Kubota K, Kosaihira S, Hino M, et al; East Japan Chesters Group: Alternating chemotherapy with amrubicin plus cisplatin and weekly administration of irinotecan plus cisplatin for extensive-stage small cell lung cancer. Anticancer Res 33: 1117-1123, 2013.

16. Kikuchi R, Isowa N, Tokuyasu H, Kawasaki Y, Onuma H, Miura H, Terada M, Takada T, Gejyo F, Suzuki E, et al: Three cases of resected pleomorphic carcinoma. Ann Thorac Cardiovasc Surg 16: 264-269, 2010.

17. Tanaka J, Tajima S, Ito R, Shimaoka Y, Kuriyama H, Kagamu H, Terada M, Takada T, Gejyo F, Suzuki E, et al: Non-small cell lung carcinoma dying of acute respiratory failure due to aerogenous metastasis. Nihon Kokyuki Gakkai Zasshi 47: 652-657, 2009 (In Japanese)

18. Van Arsdale SA: Chest mass mimicking an implanted port. Clin J Oncol Nurs 12: 673-674, 2008.

19. Wampler GL, Ahlgren JD, Lokich JJ, Gullo JJ and Phillips JA: Dichloromethotrexate, infusional cisplatin, and infusional 5-fluorouracil for locally advanced or metastatic non-small cell lung cancer. A MAOP study. Am J Clin Oncol 14: 442-445, 1991.

20. Belch AR, Urtasun RC, Bodnar D, Kinney B and Amy R: Use of hemibody irradiation as a non-cross-resistant agent in combination with systematic chemotherapy in small cell lung cancer. NCI Monogr 11: 271-274, 1988

21. Evans WK, Feld R, Murray N, Pater J, Shelley W, Willan A, Osoba D, Levitt M, Coy P, Hodson I, et al: The use of VP-16 plus cisplatin during induction chemotherapy for small-cell lung cancer. Semin Oncol 13 (Suppl 3): 10-16, 1986. 